\title{
Cross-functional experiential learning in the Iowa State University Business Analysis Laboratory
}

\author{
Dennis W. Field
}

Iowa State University

The Iowa State University (ISU) Business Analysis Laboratory is a cooperative endeavor consisting of partners from industry and ISU's Colleges of Business, Engineering, and Education. The lab is designed to provide a setting within which students may apply their education to real world business situations. Students work part-time in the Laboratory in multidisciplinary teams, progressing to leadership positions with superior performance over the course of a semester. Faculty members - one each from the Colleges of Business, Education, and Engineering_provide support to students during their work in the Laboratory. The faculty also team-teach an undergraduate Business Administration course (BusAd 392) associated with the Business Lab experience. The course is offered in seminar format and is comprised of instructional components (see Table 1) designed to provide students with some of the skills they require for technological problem solving, innovation, and integration.

Table 1: Instructional components

\begin{tabular}{ll}
\hline Team Skills & Faculty \\
Marketing Research Methodology & Faculty \\
Engineering Design Methodology & Faculty \\
Project Scheduling & Faculty \\
Overview of Survey Data Analysis & Faculty \\
Library Research Skills & Library Personnel \\
Business Communication & Faculty \\
Project Organization and Documentation Skills & Pappajohn Center Personnel \\
Overview of Business Partner Organization & Business Partner Personnel \\
Presentation Skills & Pappajohn Center Personnel \\
\hline
\end{tabular}

Since January 1999, administrative responsibility for the day-to-day operation of the Lab has resided with ISU's Pappajohn Center for Entrepreneurship in the College of Business. Corporate funding for the Laboratory was originally, and continues to be in large part, provided by $3 \mathrm{M}$, a worldwide corporation well known for technological innovation. Prior to each semester, students are recruited and asked to submit applications and resumes for the upcoming semester. Second semester students review the applications and resumes and, with input from faculty and 
Pappajohn Center personnel, make the decision as to which students will be invited to participate. The popularity of the Business Lab experience has made this a highly competitive process; typically, less than one-half of the applicants are offered positions with the Laboratory. Two Phase II scholars, Jason Becker (Marketing) and Aaron Saunders (Chemical Engineering), were asked to describe the "hiring" process. Becker stated that all of the currently participating students have input on which students are hired for the lab. Becker and Saunders said they look for many qualifications in potential candidates for the lab. Saunders went on to explain,

We look for technical skills, of course. Beyond that, we look for things like how they'd react in a situation, how skilled they are in finding alternatives and what kind of resources they would use. We ask them questions where there's really no best answer; we want to see the way they think. ${ }^{[1]}$

Students participating in the Business Lab are classified as either Phase I and Phase II scholars. Phase I scholars are in their first semester at the Lab and receive three semester hours academic credit for the experience. The Phase II scholars are chosen from Phase I graduates, and are in at least their second semester of work at the Lab. They are chosen for the Phase II part of the program based on past project performance and demonstrated leadership skills. They continue with the Business Lab as paid employees and assume some additional roles as project and human resource managers. A 2:1 ratio of Phase I to Phase II scholars is considered desirable. A typical number of students participating in the program is 24, with six students (two Phase II and four Phase I scholars) assigned to each of four projects.

\section{History of the Business Lab}

The ISU Business Laboratory is an outgrowth of 3M efforts during the early 1990s to investigate innovative ways of partnering with academic institutions. The Ames site of the $3 \mathrm{M}$ Business Laboratory opened in 1997 at a research park located near the campus of Iowa State University. In January 1999, the Pappajohn Center for Entrepreneurship formally took over administrative duties for the ISU Business Lab. The Center has four primary areas of service: Business Development, Academic Curriculum, Programs, and the Business Lab. Its charter includes providing educational courses, programs and outreach services to develop the entrepreneurial interests of Iowa State students, faculty and other Iowans. ${ }^{[1]}$

Goals and objectives of the Business Lab

The overarching goal of the Business Analysis Laboratory is simply to provide students with practical business experience within a context that benefits both the students and the corporate partners. Russ Laczniak, previous faculty representative from the College of Business, reports that it was, and still is, a priority of the College of Business, and its former Dean (Ben Allen), to give students an experience beyond the classroom. The Business Laboratory has fit in very well within the framework of the university, and provided a culture mixed between the classroom and industry. ${ }^{[1]}$ Michael Upah, Program Coordinator at the Pappajohn Center described the Business Lab in the following words:

This opportunity is win-win-win. It really is. This is an invaluable learning opportunity for students where they learn to work in small teams made up of people with both 
business and technical backgrounds. It gives [industry] ... some of the very best and brightest students they could have work on their projects, and the University gains a practical learning environment where students are trusted to help businesses make multimillion dollar decisions. ${ }^{[1]}$

Students work on different projects; some deal particularly with marketing research while some are more engineering-oriented. One notable positive related to the Business Laboratory is its capacity to expose students to the cross-functional nature of real projects, and put those students in situations that require them to move outside of their academic comfort zones. Saunders and Becker $^{[1]}$ both echo this theme in their comments. Saunders said, "I'm an Engineer, but I get to see the business side of things. They don't really teach me that in any of my classes." While Becker pointed out that:

This job shows you that you can learn different disciplines regardless of your major, but you pretty much have to be a self-starter. It's not all laid out for you. We're told what they want, and they say 'Go for it!' You've got to find out what you'll need to do to accomplish the task.

The semester projects culminate in student presentations to key members of their sponsoring organizations. The audience can include everyone from engineers or first-line supervisors; to department, product, or project managers; to corporate vice-presidents. Michael Upah has accurately judged the impact this has on students when he says, "When you're put on the spot and challenged to deliver - when failure is more than just a bad grade - you end up with motivated learning. That's powerful." [1]

Theoretical foundations

Students bring a variety of learning styles to the classroom. One cannot assume that traditional lecture formats accompanied by practice problems will build the kind of academically oriented "hands-on" practitioners so desired in new Industrial Technology graduates. One promising option involves the expanded use of learning in context; a concept employed to a great extent in the Business Laboratory. As related by Hull ${ }^{[2]}$, contextual learning is a term used to describe an overall philosophy of learning that helps students make connections between academic concepts and the workplace. He states that:

Traditionally, students have been expected to make these sorts of connections on their own, outside the classroom. However, more teachers are finding that most students' interest and ability in academics improve dramatically when they are helped to make the connection. ... Students' involvement in schoolwork increases significantly when they are taught why they are learning concepts and how these concepts are used outside the classroom. And most students learn much better when allowed to work cooperatively with other students. (p. 31)

Contextual learning has been endorsed by a number of other researchers ${ }^{[3],[4],[5]}$ as well as an effective process for education. Expanding the use of contextual learning in the Industrial Technology (IT) degree program does not require a major shift in direction; indeed, most IT 
programs already emphasize "learning by doing." What it does require is explicit attention to a goal of providing students alternatives to lecture-based learning experiences.

In the Iowa State University Industrial Technology program, one such alternative is the Business Laboratory. Cross ${ }^{[6]}$ lists a number of reasons why this sort of alternative learning experience appeals to people; among them, it incorporates Dewey's notions of learning while doing and demands the kind of disciplinary integration that is required in addressing real problems. In addition, these kinds of collaborative interactions have been shown to increase student academic performance, student retention, structured thinking, and improved ability to work together. ${ }^{\text {[7] }}$ There are unique opportunities to expand contextual learning in Industrial Technology by integrating and building on existing learning concepts such as the Business Laboratory.

Students are not the only beneficiaries of this approach. Faculty members incorporating contextual learning activities benefit by the opportunity to provide their students with more realistic problems, and by furthering their students' understanding of the interrelationships of various technical disciplines that are encompassed by Industrial Technology at ISU. Placing foundation materials in the context of professional practice increases interest levels and retention rates of new students. This process of contextual learning also helps faculty more realistically assess student learning by tying student outcomes to specific tasks.

\section{Business Lab projects}

Projects undertaken by Business Laboratory students are provided by the corporate partners who identify actual projects within their own operations that meet two criteria-they must be of real value to the corporate partners and must have objectives that can be reached by student teams over the course of a semester. Projects may occasionally develop into multi-semester efforts, and be handed off from one group to another, however every attempt is made to delineate an achievable set of objectives for each semester's group of students. The majority of these activities demand that students possess or develop competencies in solving technical problems or use technology in innovative ways to address business-related questions. An excellent example involved the use of cluster analysis for market segmentation.

Choices associated with allocation of scarce resources must be made by individuals at all levels of organizations. Businesses do not have unlimited resources, and choices must routinely be made as to where to focus all available resources, including human resources. Marketing and sales departments, for example, may attempt to classify prospective customers by potential for purchasing their products; those with the highest potential would then be targeted by the marketing and sales staff. As markets become increasingly global, the sheer volume of potential customers can rapidly exceed a company's ability to qualify them on an individual basis. However formal classification and grouping techniques exist that can assist companies in identifying similarities and differences among potential customers, which may then be used to fine-tune the companies marketing and sales strategies. One such technique is cluster analysis. Finerty ${ }^{[8]}$ has suggested the use of cluster analysis as a data mining technique to uniquely group customers for customized treatments. Green, Wind, Drieger, and Saatsoglou ${ }^{[9]}$ place cluster analysis on the list of quantitative marketing research modeling techniques that have seen "phenomenal" growth over past years. During three previous semesters, a Business Lab team has learned and applied cluster analysis to marketing datasets containing multiple variables on 
325,000 to 650,000 individual cases. The sheer size of the dataset posed a number of technical problems, not the least of which was identifying and locating hardware and software powerful enough to handle this dataset. The contrast between this kind of real-life problem to which the Business Lab students are exposed and the kind of textbook problems students might see in a typical master's level multivariate statistics course is exemplified by the size of the datasets. The Business Lab students worked with datasets ranging from 325,000 to 650,000 individual cases, while the maximum number of cases proposed for use in student exercises in Johnson and Wichern's ${ }^{[10]}$ Applied Multivariate Statistical Analysis text was less than 60.

\section{Assessment}

Anecdotal evidence points to a high level of satisfaction with the experience among students, faculty, and corporate partners; however, a more formal assessment of program outcomes is needed and underway. Current efforts related to assessment in this non-traditional learning environment are currently limited to an evaluation of Phase I student performance by Phase II students and, recently, to student interviews.

The peer assessments are provided to the faculty, who then make a decision regarding the "pass/fail" grade that is to be reported to the registrar. These peer assessments are primarily informational in nature, as it is extremely rare for a student to "fail" this experience-those who do receive a failing grade are typically students that have stopped participating altogether in the project work. The peer assessments include both qualitative and quantitative sections, and both of these sections are further divided into four areas of concern: Attributes, Quality of Work, Attitude, and Interpersonal Relations. In the qualitative section, space is simply provided for an open-ended assessment of students' performance strengths and performance improvement needs in each of these four areas. In the quantitative sections, students are ranked on an integer scale that includes 4 (excellent), 3 (above average, 2 (average), and 1 (below average) for the four areas (see Table 2).

While it is important to communicate perceptions of their performance back to individual students, this student assessment process contributes little to the overarching issue of program assessment and evaluation from the perspectives of most of the stakeholders. One could ask, for example, what is the value of the Business Laboratory program to the College Deans and the senior executives from industry who have made the decisions to establish and fund the Business Laboratory. One should also ask, what is the meaningfulness of the Business Lab experience from the perspective of the students or the industrial participants with whom the students work on a weekly basis? The open-ended nature of these kinds of questions indicates the need for a strong qualitative component in the overall evaluation.

No other programs offering this type of experiential learning have been identified, precluding the opportunity to build upon an existing model for learning outcomes assessment in such an environment. However, the National Science Foundation $[\mathrm{NSF}]^{[11]}$ provides concise descriptions and comparisons of common qualitative techniques, several of which could be used during the course of the Business Lab assessment and evaluation program. Observation is listed among these common techniques. Potential opportunities for observation include a variety of Business Lab activities, such as student-to-student (within team) interactions, student team meetings with 
faculty, student team meetings with industrial partners, and end-of-semester project presentations to industrial partners.

Interviewing is also listed as a common technique. Use of the interview allows the investigator to pursue the answer to a number of open-ended questions from a variety of stakeholders. An initial round of interviews has been conducted with students, and plans are underway to expand the interviews to the three College Deans and their faculty representatives, and the industrial partners (management and program participants). Many resources, not the least of which are time and money, are expended to ensure continued availability of the Business Laboratory experience. The expenditures of these resources must be balanced by the perception of tangible or intangible benefits, most of which are expected to have little to do with a balance sheet bottom line.

The students do view the Business Lab as a desirable experience, although as might be expected, there were suggestions for improving the structure. Among the benefits listed by students during interviews were the following:

- Problems are rarely as well defined as might be found in the classroom. Students are faced with problems that often have less-than-clear objectives or paths to solution. They must learn to deal with ambiguity.

- The sheer volume of data encountered in a real life project can be a significant challenge. Students learn to attack problems in stages, evaluating potential solutions on smaller representative samples of data before attempting to analyze massive data sets. Problem solving skills are developed.

- Students learn how to deal with rejection and frustration as they deal with business people during their efforts to collect data. They learn how to approach busy professionals and enlist their aid in gathering data. They gain an appreciation of time constraints that their contacts are under, and that they must thoroughly prepare themselves for contact, whether face-to-face or by telephone, so that time is not wasted. They learn that they may have to rely on other members of their team to complete the project.

- Students learn that professionals can, and do, make mistakes that affect their ability to complete a project in a timely manner. They learn how to move on from these kinds of mistakes without holding a grudge.

- Finally, students mentioned that they learned that cross-functional teams are not just something they study about in their curricula, but a viable and often needed approach to solving a business problem.

Subsequent rounds of interviews will explore the questions such as: What are the desirable features of the lab from the perspectives of the three College Deans? What are the desirable features of the lab from the perspectives of the industrial partners? Is it an investment expected to yield returns, or do the partners support the Lab for primarily philanthropic reasons?

Finally, one can also obtain information useful in the evaluation process through document studies and information flow analysis. $\mathrm{NSF}^{[11]}$ suggests that existing records can provide insights into a group of people that cannot be observed or noted in another way. Popham ${ }^{[12]}$ notes that 
portfolios are applicable to assessing students' work in a variety of subject areas, and goes on to state that portfolios have been warmly embraced by those educators who regard traditional assessment with less than enthusiasm. Project team reports-provided to the industrial partners during the final presentation at semester's end by students-offer the kind of realistic portrayal of student skills and accomplishments so valued in the aforementioned portfolios.

Table 2: Performance traits

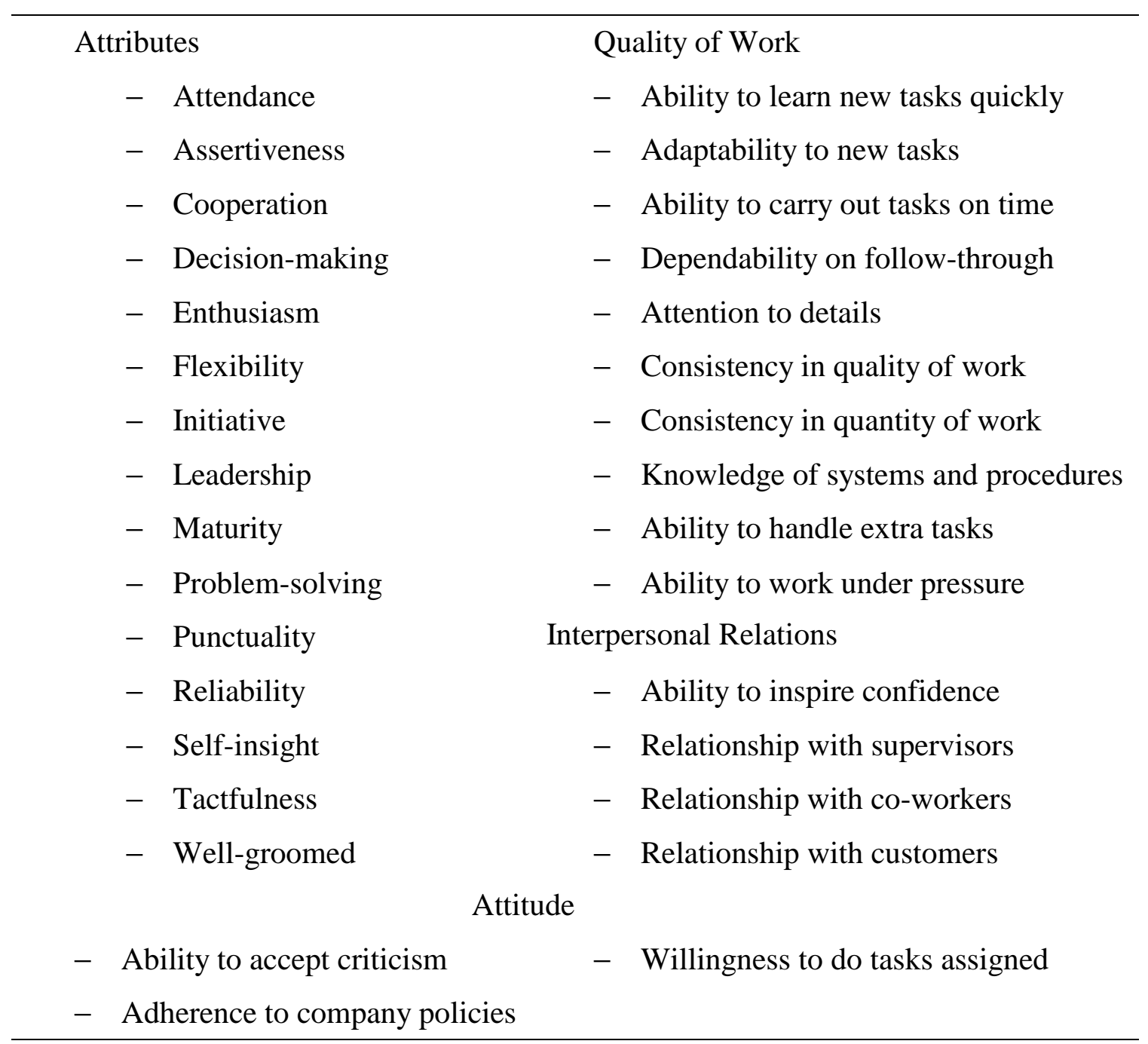

\section{Recommendations}

Education and training programs are evaluated for many reasons: to determine their value ${ }^{[13]}$, their effectiveness ${ }^{[14]}$, their quality, and to suggest opportunities for improving upon them ${ }^{[15]}$. While the anecdotal evidence points to a high level of satisfaction with the experience among students, faculty, College Deans, and corporate partners, this program is at a stage where a more detailed evaluation is needed to support informed programmatic decision-making with respect to the Business Analysis Laboratory. 
References

1. ISU Pappajohn Center. (2000). ISU Business Lab. [On-line]. Available: http://www.isupjcenter.org/BusinessLab.html

2. Hull, D. (1995). Who are you calling stupid? Waco, TX: Center for Occupational Research and Development, Inc.

3. Keif, M. G., \& Stewart, B. R. (1996). A Study of Instruction in Applied Mathematics: Student Performance and Perceptions. Journal of Vocational Education Research, 21 (3). 3148.

4. Resnick, L. B. \& Klopfer, L. E. (Eds.). (1989). Toward the Thinking Curriculum: Current Cognitive Research. Alexandria, VA: Association for Supervision and Curriculum Development.

5. Secretary's Commission on Achieving Necessary Skills. (1991). What Work Requires of Schools: A SCANS report for America 2000. Washington, DC: U.S. Department of Labor.

6. Cross, K. P. (1998). Why learning communities? Why now? About Campus, July-August: 411.

7. American Association for Higher Education, American College Personnel Association, and National Association of Student Personnel Administrators. (1998). Powerful partnerships: A shared responsibility for learning. Washington, DC: Author.

8. Finerty, P. (1997). Improving customer care through knowledge management. CMA Management Accounting Magazine, 71(9). 33.

9. Green, P. E., Wind, Y., Krieger, A. M., and Saatsoglou, P. (2000). Applying qualitative data. Marketing Research, 12(1). 17-25.

10. Johnson and Wichern. (1992). Applied Multivariate Statistical Analysis $\left(3^{\text {rd }}\right.$ ed.). Englewood Cliffs, NJ: Prentice Hall.

11. National Science Foundation. (1997). User-friendly handbook for mixed method evaluations (NSF Publication No. NSF 97-153). Washington, DC: U.S. Government Printing Office.

12. Popham, W. J. (2000). Modern educational measurement: Practical guidelines for educational leaders $\left(3^{\text {rd }}\right.$ ed.). Needham, MA: Allyn \& Bacon.

13. Tracy, W. R. (1992). Designing training and development systems (3rd ed.). New York, NY: AMACOM.

14. Kirkpatrick, D. L. (1996). Evaluating training programs: The four levels. San Francisco, CA: Berrett-Koehler Publishers, Inc. 
15. Joint Committee on Standards for Educational Evaluation. (1994). The program evaluation standards: How to assess evaluations of educational programs $\left(2^{\text {nd }}\right.$ ed.). Thousand Oaks, CA: Sage Publications, Inc.

\section{DENNIS W. FIELD}

Dr. Field is an Assistant Professor in the Department of Industrial Education and Technology at Iowa State University. 